\title{
PLANT COMMUNITY DISTRIBUTION AND DYNAMICS \\ IN BRYCE CANYON NATIONAL PARK
}

\author{
David W. Roberts \\ Utah State University \\ Logan
}

\section{Objectives}

The research status for the first year is presented under the following objectives:

1. To integrate the existing information on plant communities of Bryce Canyon National Park into the proposed research;

2. To determine the appropriate level of detail for implementation of the successional classification, and to prepare a preliminary community type classification;

3. To determine the suitability of draft SCS Ecological Site Types as non-forest habitat types;

4. To begin collection of field data necessary for development of the proposed vegetation classifications;

5. To collect sufficient ground truth for creation of an extrapolative mapping system to map large areas of the Park; and

6. To identify and characterize the distributions of rare or endangered plants within the Park.

1. To integrate the existing information on plant communities of Bryce Canyon National Park into the proposed research.

We have obtained for this research:

1.1. detailed soils maps prepared on 7.5 minute USGS ortho-photo quads

1.2. the soil survey information describing the soils and environments of the soil maps

1.3. black-and-white aerial photographs of Bryce Canyon National Park and adjacent areas

1.4. copies of unpublished research conducted in Bryce Canyon National Park

1.5. copies of all published research from Bryce Canyon National Park

To date, the obtained materials have proven useful in a number of areas of our research. The aerial photos and soil maps are being used in preparation of the extrapolative mapping guides. Sample plots have been located on soils maps and air photos for determination of relevant soils information and characteristic "signature" of vegetation types on air photos.

We are in the process of classifying the soil units mapped by the SCS into classes with properties which affect vegetation distribution. These pooled soil 
classes will then be transferred onto overlays for the USGS topo maps and included in the data base.

Published and unpublished research has been used to assist us in three principal areas:

1.6 identification and distribution of vascular plant flora

1.7. identification and expected distribution of rare or endangered plant species

1.8/. fire history and land use history within Bryce Canyon National Park

The flora of this portion of Utah is complex, with representatives of several regional flora. The lack of a standard taxonomic treatment for this area has hindered identification of unknowns and determination of appropriate nomenclature for several groups. The published checklist of the flora of Bryce Canyon National Park (Buchanan and Graybosch 1981) has greatly aided in learning the flora. However, problems in determining the appropriate taxa for many species of plants have been aggravated by the use of several different taxonomic treatments for different families of plants, as well as by the renaming of many voucher specimens in the Park herbarium to names which are not included in any of the recognized treatments. We are expecting the publication of a formal "Flora of Utah" (Welsh et al,, in press) before the next field season, and are anticipating updating all taxonomy to the new treatment. Dr. L. Shultz (curator of the Intermountain Herbarium) is assisting in identification of voucher specimens.

The information in the fire history and land use study is being applied in two areas: the development of the successional pathways models and the attempt to find relatively undisturbed relict areas.

2. Determining the appropriate implementation for the com munity type classification, and preparing a preliminary classification

All forest habitat types now have a preliminary community type classification developed, and all sample plots have been classified for com munity type. We have modified the guidelines of Steele (1984) to better implement a successional pathway model which is superimposed on the classification. The general approach is to identify the least shade tolerant species with significant basal area in the stand as the indicator species. The community types are then derived by assigning plots a membership value in seral classes which reflect the indicator species and the relative abundance of the other species in the stand. The method employs fuzzy set theory as the underlying mathematics of the model to classify seral stands by membership in fuzzy sets representing successional stages. This approach allows efficient use of field data, and provides a natural interface to a modeling approach. The details of this approach were presented by Roberts (1986).

The community type classifications indicate that the majority of the forest vegetation in Bryce Canyon National Park should be considered as mid-seral. In the majority of stands, the climax tree species is established and occasionally dominant, but generally seral species are still well represented. Table 1 lists the 
Table 1. Habitat types and community types of Bryce Canyon.

PIPO/ARNO - Pinus ponderosa / Artemisia nova

$\mathrm{N}=2$

PIPO/PUTR - Pinus ponderosa / Purchia tridentata

$\mathrm{N}=3$

PIPO/ARPA - Pinus ponderosa / Arctostaphylos patula

$\mathrm{N}=17$

$35 \%$ JUSC/PIPO community type

65\% PIPO/PIPO community type

PSME/ARPA - Pseudotsuga menziesii / Arctostaphylos patula

$\mathrm{N}=19$

$3 \%$ PIFL/PIFL com munity type

$8 \%$ PIFL/PIPO community type

$6 \%$ PIFL/PSME community type

$58 \%$ PIPO/PIPO community type

$2 \%$ PIPO/JUSC community type

24 \% PIPO/PSME community type

PSME/BERE-PIPO - Pseudotsuga menziesii / Berberis repens - Pinus ponderosa $\mathrm{N}=2$

PIPU/JUCO - Picea pungens / Juniperus communis

$\mathrm{N}=2$

ABCO/ARPA - Abies concolor / Arctostaphylos patula

$\mathrm{N}=20$

$2 \%$ PIFL/PIFL community type

5\% PIFL/PIPO community type

$5 \%$ PIFL/PSME community type

$48 \mathrm{PIFL} / \mathrm{ABCO}$ community type

$38 \%$ PIPO/PIPO com munity type

$16 \%$ PIPO/PSME' community type

$26 \%$ PIPO/ABCO com munity type

$1 \%$ PSME/PSME community type

4 \& $\mathrm{PSME} / \mathrm{ABCO}$ community type

ABCO/JUCO - Abies concolor / Juniperus com munis $\mathrm{N}=4$

68 PIFL/PIFL community type

$20 \%$ PIFL/ABCO community type

$16 \%$ PIPO/PIPO community type

$11 \%$ PIPO/PSME community type 
9: PIPO/PIPO community type 40 \% PIPO/ABCO community type

$\mathrm{ABCO} / \mathrm{BERE}$-BERE - Abies conclolx / Berberis repens - Berberis repens $\mathrm{N}=11$

$1 \%$ POTR/POTR community type

$2 \%$ POTR/PIPO community type

6 \& POTR/ABCO community type

$68 \mathrm{PIFL} / \mathrm{PSME}$ community type

38 PIFL/ABCO community type

158 PIPO/PIPO community type

$27 \%$ PIPO/PSME community type

$418 \mathrm{PIPO} / \mathrm{ABCO}$ community type

ABCO/BERE-JUCO - Abies concolor / Berberis repens - Juniperus com munis $\mathrm{N}=2$ 
relative abundance of each successional type within the appropriate habitat type where the number of plots equals four or more.

Community type classifications have not yet been developed for non-forest communities. This is a reflection of the state of classification of non-forest habitat types, and is discussed below under objective 3 .

3. To determine the suitability of draft SCS Ecological Site Types as non-forest habitat types

In general, the great majority of Bryce Canyn National Park is wooded or forested, and is included in the forest habitat type classification. Areas not included are:

1. Artemisia nova - grasslands in alluvial valleys within the Park

2. Pinus ponderosa - Pinus edulis - Juniperus scopulorum com munities on the north and east boundaries of the Park

3. Badlands and Breaks within the Park

We have identified eight ecological site types within these areas as the types are currently defined. Many of these types differ only in characteristics of the soil, however, and support very similar plant communities. Unfortunately, the SCS has made very little progress in refining the draft types. Additionally, the types are difficult to use in combination with the forest habitat types due to a different methodology of classification.

Accordingly, we are adopting a worst case philosophy with regards to the non-forest habitat types. We are targeting these types for increased sampling next field season, and will produce a non-forest habitat type classification which is in better agreement with the methodology and procedures used in the forest habitat type classification. These non-forest habitat types will then be cross-referenced to the draft SCS types, rather than derived from them. This approach offers the advantage of greater uniformity of classification, allows us to complete the work independent of the pace of the SCS, and still allows us to incorporate data included in the draft types where possible.

4. To begin collection of the data necessary for the development of the classifications

During the field season of 1986, a total of 87 sample plots were collected, distributed throughout the Park. Sample plots included estimates of the cover of all vascular plant species, basal area of all tree species, age of oldest trees of each species, elevation, aspect, slope, and parent material. All sample plots were classified by habitat type and community type. Table 1 lists the habitat types, the number of plots in each type, and the relative distribution of community types within the habitat type where the number of plots equals 4 or more.

For the forested portion of the Park, the distribution of habitat types is relatively well known. The Park contains five series: Pinus ponderosa, Pseudotsuga menziesii, Picea pungens, Pinus flexilis - Pinus longaeva, and Abies 
concolor. Experience has shown that the forest habitat types as defined by Youngblood and Mauk (1985) are in reasonable agreement with the vegetation of Bryce Canyon National Park, and the creation of any new forest habitat types is probably not required.

Our general understanding at this point is that the habitat types are distributed according to available soil moisture, soil drainage, exposure, and precipitation inputs. Low elevation sites fall into the PIPO/ARNO, PIPO/PUTR, and PIPO/ARPA habitat types. PIPO/A RNO reflects lower timberline and toe slopes within the plateau area, where the soils are generally alluvial, and partly saturated for part of the season, while being well-drained to excessively well-drained at other points in the year (A. Winward, personal com munication, Youngblood and Mauk 1985). PIPO/PUTR occupies benches and toe slopes where soils are well drained, on sites that are relatively cool for this elevational zone. PIPO/ARPA generally occupies lower and mid-slopes which are well-drained and warm, or subject to high evaporative demand.

With increasing available moisture, Pseudotsuga menziesii becomes the climax dominant. The majority of the Pseudotsuga menziesii series is in the PSME/ARPA habitat type. These sites are similar to the PIPO/ARPA habitat type, but apparently have greater moisture availability at lower points of the rooting zone.

With additional moisture, Abies concolor becomes climax, with a total of four habitat types and phases represented. The minimum moisture requirement of Abies concolor appears to be very similar to Pseudotsuga menziesii in Bryce Canyon National Park, so that climax Pseudotsuga forests often occupy a relatively narrow band between the Pinus ponderosa series and the Abies concolor series. Relatively warm dry sites within the A bies concolor series are in the ABCO/ARPA habitat type, with understories similar to the PSME/ARPA habiat type, although supporting somewhat greater cover. Intermediate sites are occupied by $\mathrm{ABCO} / \mathrm{JUCO}$, with more mesic sites occupied by $\mathrm{ABCO} / \mathrm{BERE}$.

The Picea pungens series, with the PIPO/JUCO habitat type, appears to occupy a unique topo-edaphic site characterized by coarse colluvial soils and accumulation of cold air drainage. These sites typically occur on toe slopes of mountains or ridges facing into in narrow canyons. The Pinus flexilis - Pinus longaeva series also occupies unique topo-edaphic sites. These sites are generally extremely exposed, and occur on coarse colluvial soils with excessive drainage.

While the defined habitat types appear to fit relatively well, some modification of the distribution of seral tree species may be indicated. Youngblood and Mauk (1985) apparently never observed Pinus edulis in the PIPO/ARPA habitat type (Appendix B. Pg. 68), whereas we observe this species in the dry end of the type. Youngblood and Mauk employed an arbitrary cutoff paint of $25 \%$ crown cover for sampling, where some of our samples may support lower cover. Essentially, the PIPO/ARPA type in Bryce Canyon National Park appears to grade into the Pinus edulis. 
Youngblood and Mauk (1985) also list Juniperus scopulorum as a minor co-climax species in the PSME/ARPA and ABCO/ARPA habitat types. While Juniperus scopulorum does occur in these types in Bryce Canyon National Park, we have never observed this species in the absence of other seral conifers. It seems likely that crown closure sufficient to exclude Pinus ponderosa and Pinus flexilis from these stands would also exclude Juniperus scopulorum, but we have been unable to determine whether or not this is true. Consequently, in the preliminary community type classifications, Juniperus scopulorum is treated as a potential co-climax as indicated by Youngblood and Mauk.

5. To collect sufficient ground truth for creation of an extrapolative mapping system to map large areas of the Park

In addition to the 87 sample plots, approximately 15,000 acres of Park land were habitat type mapped for development of habitat type mapping guides. The habitat type distributions are being overlayed with the soils map to develop information for input to a classification and regression tree (CART) analysis (Breiman et al. 1984). The ground truth represents numerous individual stands, and will supply sufficient information for an initial predictive model using CART. We have computer coded the site attributes of the sample plots for input to CART, but have not yet computer coded the data represented by the area mapped.

6. To identify and characterize the distributions of rare or endangered plants within the Park

No Federally protected species are known to exist in Bryce Canyon National Park. Of the rare or endimic species listed by Buchanan and Graybosch (1981) or Graybosch and Buchanan (1983), only six remain under study for protection. Of the six, we have observed two: Psoralea pariensis and Castilleja revealii. Castilleja revealii was observed only once, as a single specimen, and it is not known whether or not this observation represents a new siting. Psoralea pariensis was observed in several patches on one site, and the observation apparently represents a new siting for this species. Accordingly, we have established a transect through similar habitat for sampling next field season to determine whether the species is relatively more wide spread than previously thought. Similar sites to the area of observation of Castilleja revealii will also be examined for possible additional populations. 